\title{
Retrieval Spectral Albedo using red and NIR band of SPOT/VGT
}

\author{
Chang Suk Lee, Min Ji Seo and Kyung-Soo Han'
}

Department of Spatial information Engineering, Pukyong National University

\begin{abstract}
Albedo is one of the critical parameters for understanding global climate change and energy/water balance. In this study, we used red and NIR reflectance from Satellite Pour I'Obervation de la Terre (SPOT)/ Vegetation (VGT) S1 product. The product is preprocessed for users that they are atmospherically corrected using Simple Method Atmospheric Correction (SMAC) by Vision on Technology (VITO) for calculating broadband albedo. Roujean's Bi-directional Reflectance Distribution Function (BRDF) model is a semi-empirical method used for BRDF angular integration and inversion. Each kernel of Roujean's model was multi integrated by angle components (i.e., viewing zenith, solar zenith, and relative azimuth angle). Black-sky hemispherical function is integrated by observational angle; whereas, white-sky hemispherical efficient is integrated by incident angle. Estimated spectral albedo of red $(0.61 \sim 0.68 \mu \mathrm{m}, \mathrm{B} 2)$ and near infrared (0.79 $0.89 \mu \mathrm{m}, \mathrm{B} 3)$ have a good agreement with MODIS albedo products.
\end{abstract}

Key Words : spectral albedo, SPOT/VGT, time series

\section{Introduction}

Land surface albedo is represented by the ratio of the radiant flux reflected from the Earth's surface to the incident flux, and it is a key parameter in weather predictions and understanding the surface energy balance (Schaaf, 2009). A lot of studies previously reported that surface albedo has feedback relationship between land and atmosphere, and it affects climate and vegetation cover (Henderson-Sellers and Wilson, 1983; Dickinson, 1995; Avissar and Verstraete, 1990; Lucht et al., 2000). In addition, global surface albedo had been selected as one of Essential Climate Variables (ECVs) by Global Climate Observation System (GCOS) for characterizing the conditions of global climate and effects from natural and anthropogenic forcing (GCOS, 2003, 2006; Govaerts et al., 2008).

For observing and forecasting of climate change for global-scale, grid data covers the entire surface of the Earth so that it does not need the form of point measurements which generally from field. From this perspective, satellite remote sensing is the most effective way to mapping global surface albedo. Most of the multi-spectral sensors observe in narrow spectral

Received June 19, 2014; Revised June 24, 2014; Accepted June 24, 2014.

† Corresponding Author: Kyung-Soo Han (kyung-soo.han@pknu.ac.kr)

This is an Open-Access article distributed under the terms of the Creative Commons Attribution Non-Commercial License (http://creativecommons. org/licenses/by-nc/3.0) which permits unrestricted non-commercial use, distribution, and reproduction in any medium, provided the original work is properly cited 
bands. However, the energy coming into the Earth from sun is dominant in wave range of $0.3 \sim 3.0 \mu \mathrm{m}$. The estimation of spectral albedo of each band is essential intermediate step since the spectral band albedos are inputted to retrieve broad band albedo. Each spectral albedo from Satellite Pour I'Obervation de la Terre (SPOT)/VEGETATION (VGT) has not been provided to users. In this study, we tried to estimate spectral albedo using red and near infrared (NIR) of SPOT/VGT. These bands were used in a lot of sensors and commonly used for extracting information of vegetation conditions.

\section{Data and Study area}

We used daily synthesis surface reflectance (S1) product of SPOT/ VGT to retrieve broad band albedo because SPOT adopts a pushbroom (along track scanner) way which observes land perpendicular to the flight direction in line of detectors. It receives a strong signal than a whiskbroom (across track scanners) because a pushbroom observe land pixels for a longer period of time. Consequently, it has less geometric distortion because the sensors do not move from side to side on across track direction. The S1 product was synthesized only taking into account that multiple measurements obtained through the overlap between successive passes at high latitudes (Verbeiren, 2009). Also, the S1 product was already corrected for its radiometric, geometric distortion and atmospheric effects were by Simplified Method Atmospheric Correction (SMAC) which was developed by Rahman and Dedieu (1994). SPOT/VGT has four spectral channels: B0 (0.43 $0.47 \mu \mathrm{m}$, blue), B2 (0.61 0.68 $\mu \mathrm{m}, \mathrm{red}), \mathrm{B} 3(0.79 \sim 0.89 \mu \mathrm{m}, \mathrm{NIR})$, and MIR (1.58 $1.75 \mu \mathrm{m}$, middle IR). We used B2 and B3 of 2009.

As reference broad band albedo data, Moderate Resolution Imaging Spectroradiometer (MODIS) official albedo products (MCD43B3) were collected. Liang et al. (2002) showed results of validation of MCD43B3 through comparison with Enhanced Thematic Mapper Plus (ETM+) and MCD43B3. It had reasonable accuracy of less than 5\% absolute error. MODIS land cover product (MCD12Q1) was also collected as ancillary data. Fig. 1 represents the area of

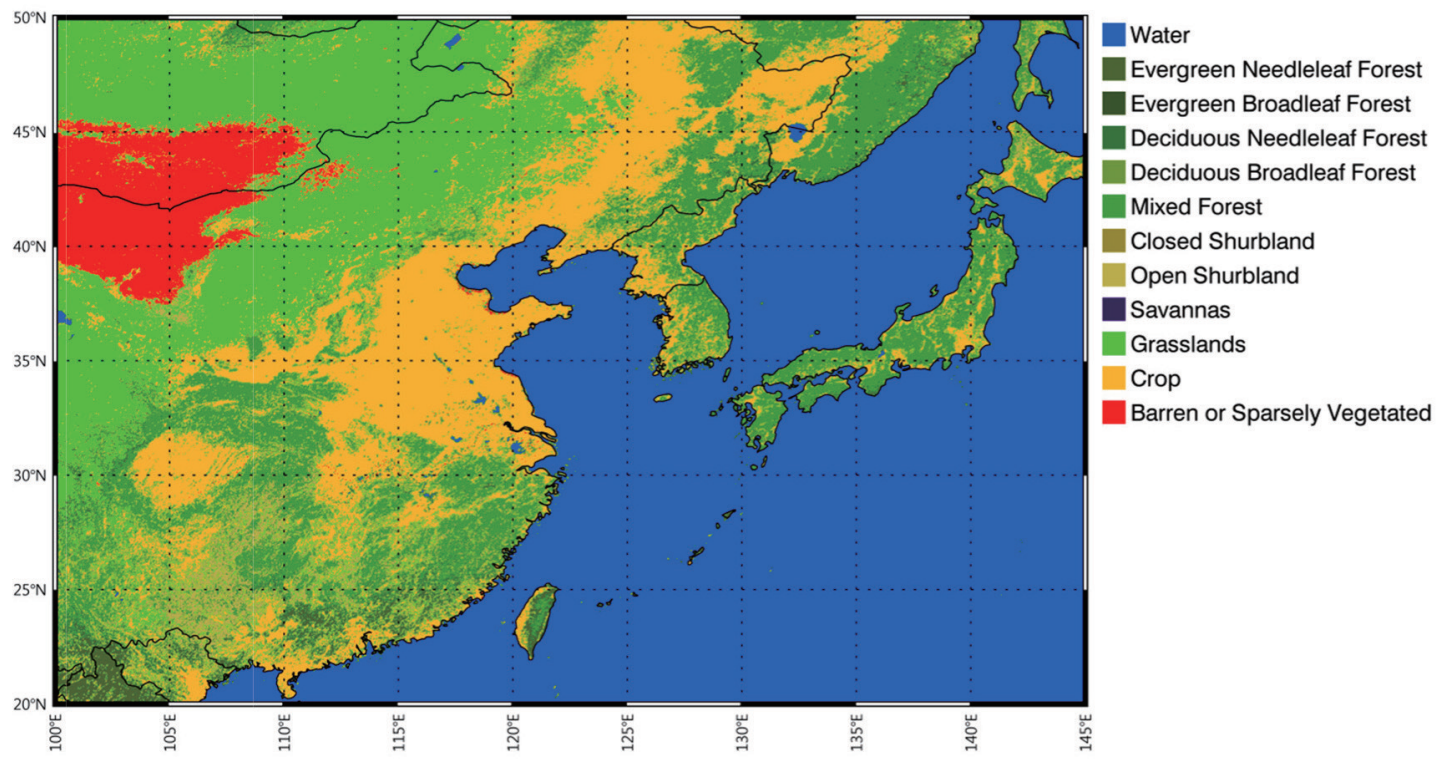

Fig. 1. Land cover map from MODIS in accordance with the study area. 
interest which shows the distribution of land type from MODIS land cover map. Our study area has dynamic interactions of vegetation, land cover and climatic change effects as stated in many previous studies ( $\mathrm{Pi}$ et al., 2009; Kim et al., 2011; Park et al., 2012).

\section{Method}

To estimate spectral albedo, Top Of Atmosphere (TOA) reflectance from space-borne optical sensors has been processed in two phases. Firstly, all of the TOA from optical sensors is affected by gas molecules and aerosols in the atmosphere. Thereby, atmospheric correction should be carried out to remove atmospheric effects. However, the SPOT/VGT S1 product already removed atmospheric effect using SMAC model. Secondly, surface albedo is related to surface reflectance which varies according to the incident and reflectance angel of light; therefore, Bi-directional Reflectance Distribution Function (BRDF) was conducted. Varied reflectance is describable by the BRDF model. Lee and Han (2013) revealed results of comparison between two semi-BRDF models: RossLi (Luchet et al., 2000) and Roujean's models (Roujean et al., 1992). It showed Ross-Li has better kernels performance; whereas, Roujean had more reasonable values in case of inversion coefficients. Semi-empirical BRDF has, in general, following equation form (Roujean et al., 1992).

$$
\rho\left(\theta_{s}, \theta_{v}, \Phi\right)=K_{0}+K_{1} f_{1}\left(\theta_{s}, \theta_{v}, \Phi\right)+K_{2} f_{2}\left(\theta_{s}, \theta_{v}, \Phi\right)
$$

The semi-empirical model consists of three parts, the first is about isotropic scattering, the second is geometric scattering, and the last part is volumetric scattering. Each part has their empirical coefficients $\left(K_{0,1,2}\right)$ and kernels $\left(f_{1,2}\left(\theta_{s}, \theta_{v}, \Phi\right)\right)$ which derived from a physical model (Wanner et al., 1995). The empirical coefficients were calculated by inversion of the BRDF model, so that are called inversion coefficients. The inversion coefficients of the BRDF model and kernel integration function were needed to estimate spectral albedo. Kernels are used to estimate albedo after the integration with directional components where the inversion coefficients are directly used. Therefore, we used Roujean's BRDF model to retrieve surface albedo. Actual albedo contains direct (black sky) and diffused irradiance by atmospheric components (white sky). These terms assume simplified atmospheric conditions: black-sky had absence of a diffuse irradiance component, and white-sky is wholly diffuse irradiance in atmosphere. Lucht et al. (2000) shows actual albedo is a value interpolated between these two extreme values. Following equation (2) and (3) describe calculations of kernels integration for blacksky and white-sky albedo.

$$
\begin{gathered}
h_{b, k}\left(\theta_{s}\right)=\int_{0}^{2 \pi} \int_{0}^{\pi / 2} f_{k}\left(\theta_{s}, \theta_{v}, \Phi\right) \sin \left(\theta_{v}\right) \cos \left(\theta_{v}\right) d \theta_{v} d \Phi \\
h_{w, k}=2 \int_{0}^{\pi / 2} h_{b, k}\left(\theta_{s}\right) \sin \left(\theta_{s}\right) \cos \left(\theta_{s}\right) d \theta_{s}
\end{gathered}
$$

where, $\theta_{s}$, and $\theta_{v}$ are solar and viewing zenith angle respectively, and $\Phi$ is relative azimuth angle between the sun and a sensor. $f_{k}$ represents each kernel (geometric and volumetric) in the BRDF model and $h_{b}$ and $h_{w}$ depicts hemispherical function of black-sky and white-sky. Fig. 2 shows the variation of values of kernel integration using equation (2) according to change of Solar Zenith Angle (SZA) and simulated line from regression equation for black-sky. Each solid line was calculated by regression equations (4) and (5) which were retrieved linear and nonlinear regression analysis with integrated kernel values per 1 SZA degree. Equation (4) is regression equation to simulate integral value of volumetric kernel, and equation (5) is to simulate integral value of geometric kernel.

$$
\begin{gathered}
h_{b, v o l}=0.261 \theta_{s}^{3}+0.291 \theta_{s}^{2}+0.148 \theta_{s}-0.021 \\
h_{b, g e o}=\left(1-0.382 \theta_{s}\right) /\left(0.625 \theta_{s}-0.982\right)
\end{gathered}
$$

Black sky function depends on change of the SZA. Fig. 2 depicts simulated equation corresponds well with 
Table 1. Result of integration for white-sky using simulated equations (4) and (5)

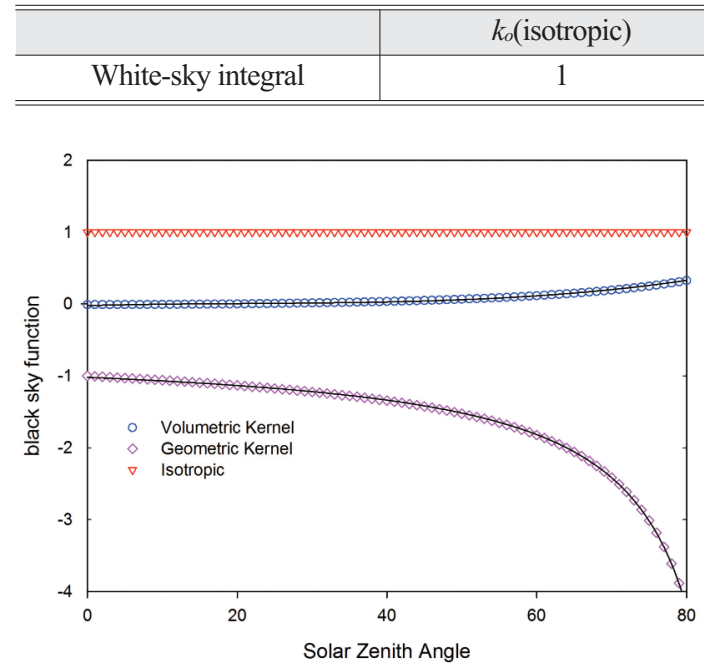

Fig. 2. Integration value of each kernel according to variation of solar zenith angle for black-sky (blue circle: volumetric, violet diamond: geometric, red triangle: isotropic).

the change of black sky function value according to SZA. As following equation (6) and (7), each kernel of the BRDF model was integrated independently and multiplied with inversion coefficients to calculate spectral albedo.
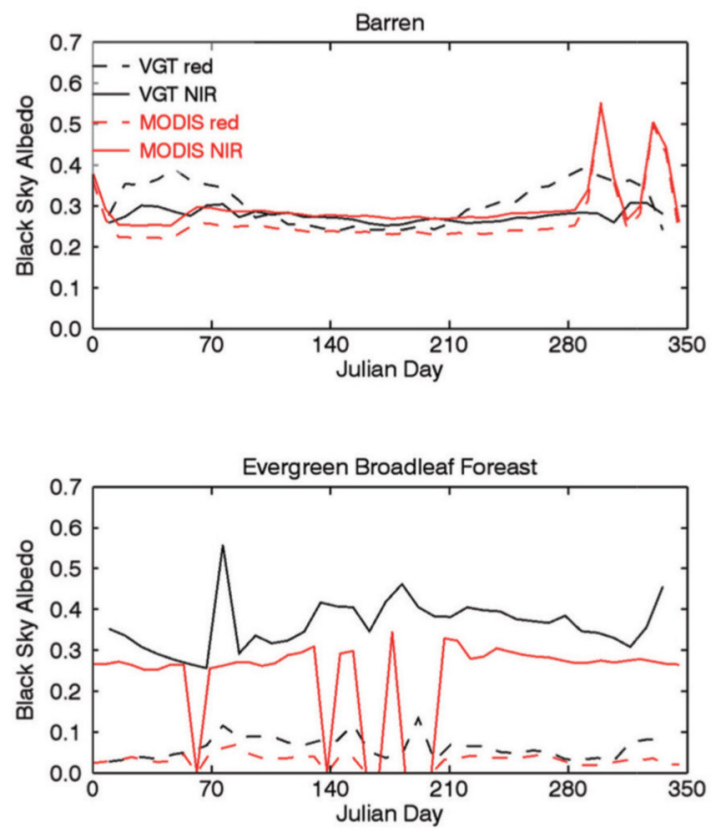

$$
\begin{gathered}
a_{b}\left(\lambda, \theta_{s}\right)=K_{0}+K_{1} h_{b, 1}\left(\theta_{s}\right)+K_{2} h_{b, 2}\left(\theta_{s}\right) \\
a_{w}(\lambda)=K_{0}+K_{1} h_{w, 1}+K_{2} h_{w, 2}
\end{gathered}
$$

So, black sky hemispherical function should be examined separately as Fig. 2. White-sky constants were retrieved by equation (3) using equations (4) and (5) (Table 1). Inversion coefficient of each kernel and integrated value of each kernel were examined through linear equation.

\section{Results \& Discussion}

We examined change patterns of estimated spectral albedo compared with MODIS official albedo product during 2009. Comparison with Spectral albedo from satellite and point measurements has scale mismatch (Liang et al., 2002) so MODIS spectral albedo products
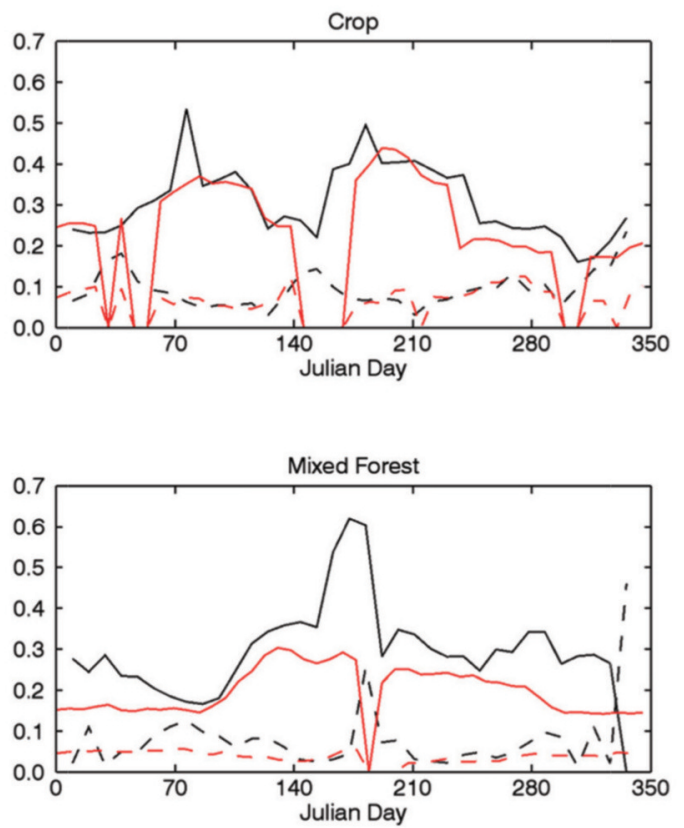

Fig. 3. Change of black-sky spectral albedo of two bands (dash: red, solid: NIR) according to four land types during 2009 (black line: calculated spectral albedo, red line: MCD43B3). 

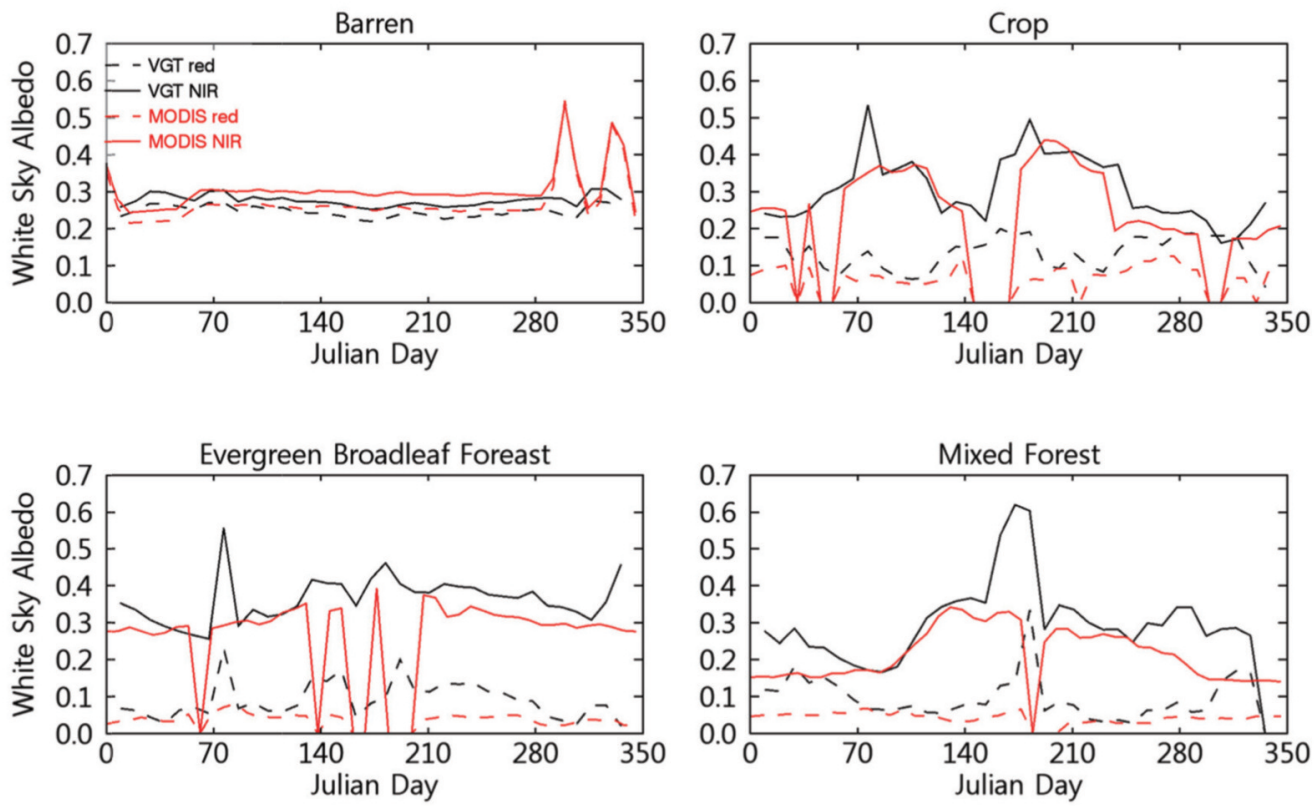

Fig. 4. Change of white-sky spectral albedo of two bands (dash: red, solid: NIR) according to four land types during 2009 (black line: calculated spectral albedo, red line: MCD43B3).

were used for validation due to similar spatial resolution and band range width. We selected several land types (barren, crop, evergreen broadleaf forest, and mixed forest) for comparison with other albedo products because characteristics of the surface albedo depend on land surface properties.

Fig. 3 and 4 showed variations of each spectral albedo according to four land types. Generally, results of comparison with converted and official albedo showed similar change patterns in most of the conditions such as land, albedo type and band. On the entire graphs, estimated albedos show little higher albedo value than MCD43B3. In MCD43B3, some albedo missing sections exist except barren land but the estimated albedos from our study have no missing section on entire period. This is because different composite period between two spectral albedos (MCD43B3: 16 days, estimated albedo: 30 days).

Crop shows better agreement with MCD43B3 than other land types. Two forest types tend to be little overestimated than MCD43B3. Converted spectral albedos have high peaks that seem to be outliers except barren land. These values may be caused by incomplete cloud mask.

\section{Conclusions}

The spectral albedo is essential intermediate product to retrieval broad band albedo, but SPOT/VGT does not provide the product. So we estimated surface spectral albedo of red and NIR using SPOT/VGT with the BRDF modeling and conversion procedures. Refer to a previously study (Lee and Han, 2013), integral kernel and inversion coefficients of Roujean's model for retrieving spectral albedos of red and NIR. Regression equation for black sky hemispherical function so well described variation of integration of kernels. We compared our estimated spectral albedo of SPOT/VGT with the MODIS official albedo product. As a result of time series analysis, the estimated spectral albedos have similar change patterns with MCD43B3. Black sky albedos have better agreement with MCD43B3 than white sky albedos. For the future 
plans, we will validate our estimated spectral albedo with the in-situ measurements or spectral library.

\section{Acknowledgment}

This work was funded by the Korea Meteorological Administration Research and Development Program under Grant CATER 2012-2066.

\section{References}

Avissar, R., and M.M. Verstraete, 1990. The representation of continental surface processes in atmospheric models, Reviews of Geophysics, 28(1): 35-52.

Dickinson, R.E., 1995. Land processes in climate models, Remote Sensing of Environment, 51(1): 27-38.

GCOS, 2003. Second report on the adequacy of the global observing systems for climate, Technical Report GCOS-82, WMO/TD No. 1143, World Meteorological Organization.

GCOS, 2006. Systematic observation requirements for satellite-based products for climate: Supplemental details to the satellite-based component of the implementation plan for the global observing system for climate in support of the UNFCCC, Technical Report GCOS-107, WMO/TD No 1338, World Meteorological Organization.

Govaers Y.M., A. Lattanzio, M. Taberner, and B. Pinty, Generating global surface albedo products from multiple geostationary satellites, Remote Sensing of Environment, 112: 2804-2816.

Henderson-Sellers, A. and M.F. Wilson, 1983. Surface albedo data for climatic modelling, Reviews of Geophysics, 21(8): 1743-1778.

Kim, S.I., K.-S. Han, and K.-J. Pi, 2011. The Trend
Analysis of Vegetation Change Applied to Unsupervised Classification Over East Asia: Using the NDVI 10-day data in 1999 2010, Journal of Korean Society for Geospatial Information System, 19(4): 153-159 (in Korean with English abstract).

Lee, C.S., and K.S. Han, 2013. Comparison of Two Semi-Empirical BRDF algorithms using SPOT/VGT, Korean Journal of Remote Sensing, 29(3): 307-314.

Liang, S., H. Fang, M. Chen, C.J. Shuey, C. Walthall, C. Daughtry, J. Morisette, C. Schaaf, and A. Strahler, 2002. Validating MODIS land surface reflectance and albedo products: Methods and preliminary results, Remote Sensing of Environment, 83(1): 149-162.

Lucht, W., C.B. Schaaf, and A.H. Strahler, 2000. An algorithm for the retrieval of albedo from space using semiempirical BRDF models, IEEE Transactions on Geoscience and Remote Sensing, 38(2): 977-998.

Rahman, H. and G. Dedieu, 1994. SMAC: a simplified method for the atmospheric correction of satellite measurements in the solar spectrum. International Journal of Remote Sensing, 15(1): 123-143.

Roujean, J.L., M. Leroy, and P.Y. Deschamps, 1992. A bidirectional reflectance model of the Earth's surface for the correction of remote sensing data, Journal of Geophysical Research, 97(D18): 20455-20468.

Park, E.-B., K.-S. Han, C.-S. Lee, and K.-J. Pi, 2012. The Tendency Analysis of Albedo by Land Cover Over Northeast Asia Using MODIS 16Day Composited Albedo data, Korean Journal of Remote Sensing, 28(5): 501-508 (in Korean with English abstract).

Pi, K.-J., K.-S. Han, and S.-J. Park, 2009. A Comparative Analysis of Land Cover Changes Among Different Source Regions of Dust 
Emission in East Asia: Gobi Desert and Manchuria, Korean Journal of Remote Sensing, 25(2): 175-184 (in Korean with English abstract).

Schaaf, C.B., 2009. ALBEDO albedo and reflectance anisotropy, Global Terrestrial Observing System, Rome.

Strahler, A.H., J.P. Muller, W. Lucht, C.B. Schaaf, T. Tsang, F. Gao, L. Xiaowen, J.P. Muller, and M.J. Barnsley, 1999. MODIS BRDF/albedo product: algorithm theoretical basis document version 5.0., MODIS documentation.

Valiente, J.A., M. Nunez, E. Lopez-Baeza, and J.F. Moreno, 1995. Narrow-band to broad-band conversion for Meteosat-visiible channel and broad-band albedo using both AVHRR-1 and2 channels, International Journal of Remote
Sensing, 16(6): 1147-1166.

van Leeuwen, W.J., and J.L. Roujean, 2002. Land surface albedo from the synergistic use of polar (EPS) and geo-stationary (MSG) observing systems: An assessment of physical uncertainties, Remote Sensing of Environment, 81(2): 273-289.

Verbeiren, S., 2009. GMES Space Component Data Access(GSC-DA) Instrument/Product specifications, VITO, p42.

Wanner, W., X. Li, and A.H. Strahler, 1995. On the derivation of kernels for kernel driven models of bidirectional reflectance. Journal of Geophysical Research: Atmospheres (19842012), 100(D10): 21077-21089. 